\title{
Treatment of Nonarteritic Anterior Ischemic Optic Neuropathy
}

\author{
Edward J. Atkins, MD ${ }^{1}$, Beau B. Bruce, MD ${ }^{1,2}$, Nancy J. Newman, $\mathbf{M D}^{1,2,3}$, and Valérie \\ Biousse, MD ${ }^{1,2}$ \\ ${ }^{1}$ Department of Ophthalmology, Emory University School of Medicine, Atlanta GA, USA \\ ${ }^{2}$ Department of Neurology, Emory University School of Medicine, Atlanta GA, USA \\ ${ }^{3}$ Department of Neurological Surgery, Emory University School of Medicine, Atlanta GA, USA
}

\section{Abstract}

Nonarteritic anterior ischemic optic neuropathy (NAION) is the most common clinical presentation of acute ischemic damage to the optic nerve. Most treatments proposed for NAION are empirical and include a wide range of agents presumed to act on thrombosis, on the blood vessels, or on the disc edema itself. Others are presumed to have a neuroprotective effect. Although there have been multiple therapies attempted, most have not been adequately studied, and animal models of NAION have only recently emerged. The Ischemic Optic Neuropathy Decompression Trial (IONDT), the only class I large multicenter prospective treatment trial for NAION, found no benefit from surgical intervention. One recent large, nonrandomized controlled study suggested that oral steroids might be helpful for acute NAION. Others recently proposed interventions are intravitreal injections of steroids or anti-vascular endothelial growth factor (antiVEGF) agents. There are no class I studies showing benefit from either medical or surgical treatments. Most of the literature on the treatment of NAION consists of retrospective or prospective case series and anecdotal case reports. Similarly, therapies aimed at secondary prevention of fellow eye involvement in NAION remain of unproven benefit.

\section{Keywords}

nonarteritic anterior ischemic optic neuropathy; treatment; pathogenesis; Ischemic Optic Neuropathy Decompression Trial (IONDT)

\section{I-Introduction}

Anterior ischemic optic neuropathy (AION) results from ischemic damage to the anterior portion of the optic nerve, a region primarily supplied by the posterior ciliary artery circulation. Anterior ischemic optic neuropathy is divided into two types: arteritic AION (AAION), secondary to vasculitis (especially giant cell arteritis), and nonarteritic AION (NAION), secondary to non-inflammatory small vessel disease. ${ }^{1,35,69}$ NAION constitutes $95 \%$ of all AION and is the most common cause of acute optic neuropathy in people over the age of 50, affecting somewhere between 2 to 10 individuals per 100,000 (approximately 1500 to 6000 new cases per year in the United States). ${ }^{34}$ Currently, no generally accepted treatment or secondary prevention of NAION exists. We review approaches suggested to treat NAION.

Address correspondence to: Valérie Biousse, MD. Neuro-ophthalmology Unit, Emory Eye Center, 1365-B Clifton Road, NE, Atlanta, Georgia 30322, Tel: 404-778-5360 Fax: 404-778-4849 vbiouss@emory.edu. 


\section{II-Clinical presentation}

Nonarteritic AION is an acute or subacute optic neuropathy resulting from small vessel infarction of the anterior optic nerve. Symptoms include acute, unilateral, usually painless visual loss that evolves over several hours to days. Visual acuity varies from 20/20 to no light perception, but remains better than 20/200 in about two-thirds of patients. Color vision is lost to a similar degree as visual acuity. Because it is an optic neuropathy, a relative afferent pupillary defect is present in unilateral forms. An arcuate or altitudinal defect, particularly in the inferior visual field, is most common (Figure 1); however, as is often the case with optic neuropathies, any region of the visual field can be affected. Funduscopy reveals disc edema acutely, often with peripapillary flame-shaped retinal hemorrhages (Figure 2). By 4 to 6 weeks the disc develops diffuse or segmental pallor. The appearance of the optic disc in the contralateral eye is almost always that of a "disc at risk", meaning that there is a small diameter, crowded optic disc with a small or absent physiologic cup (Figure 3). $1,35,69$

\section{III-Pathogenesis}

Small vessel circulatory insufficiency of the optic nerve head is the most widely accepted pathophysiology of NAION, but the location of the associated vasculopathy and mechanism of ischemia remain uncertain. ${ }^{2,61}$ The optic nerve head is supplied by an anastomotic arterial circle (derived from the short posterior ciliary arteries) with distinct upper and lower halves, consistent with the altitudinal defects often seen in NAION. ${ }^{2,69}$ Fluorescein angiography studies provide the most compelling indirect evidence that circulatory insufficiency in the paraoptic branches of the short posterior ciliary arteries is the primary cause $;{ }^{2}$ however, no adequate systematic histopathologic studies of these vessels have been performed, and it is not known whether there is associated atherosclerotic change or thrombosis. ${ }^{64}$ A series of 193 eyes with a histopathological diagnosis of ischemic optic neuropathy has been reported, ${ }^{57}$ but because no clinical details were available, those cases with a typical presentation of NAION could not be identified. Neither lipohyalinosis, occlusion, nor inflammation of the vessels was identified; however, the infarctions identified were predominantly in the retrolaminar portion of the optic nerve head, suggesting less involvement of the choroidal blood supply that primarily supplies the laminar and prelaminar layers. ${ }^{57}$ Levin and Danesh-Meyer recently proposed that NAION may be primarily a venous disease; ${ }^{65}$ however, this theory remains speculative. A recent study utilizing optical coherence tomography (OCT) demonstrated that 8 of 76 patients examined within 4 weeks of visual loss had subfoveal fluid, likely responsible for some of the reversible visual loss. ${ }^{47}$

\section{III.1 Cup to disc ratio}

Patients with a small cup to disc ratio are predisposed to NAION and are said to have a "disc at risk" (figure 3). In normal eyes there is ample room for the approximately 1,200,000 axons that constitute the optic nerve to exit the eye; however, in patients with structurally small optic discs there is no safety margin. Swelling within the confines of a tight disc may produce a "compartment syndrome", a vicious cycle of disc edema and peripapillary hemorrhages. ${ }^{2}$ The crowded axons swell in the restricted space, and capillaries and other small vessels among the nerve fibers are compressed, resulting in cytotoxic and vasogenic edema that causes infarction and tissue loss. ${ }^{36}$ Optic nerve head ischemia/hypoxia may result in secondary axoplasmic flow stasis within the optic nerve. ${ }^{70}$

Caucasians are significantly more predisposed to develop NAION than Blacks or Hispanics, most likely because Caucasians tend to have smaller cup to disc ratios with crowding of 
optic nerve head axons. ${ }^{21}$ Other optic nerve anomalies causing crowding, such as optic disc drusen and papilledema, are also associated with NAION. ${ }^{5,80}$

\section{III.2 Vasculopathic risk factors}

Diabetes, hypertension, and hypercholesterolemia are well known risk factors for ischemic small vessel disease. Arteriosclerosis or lipohyalinosis are suspected in the pathogenesis of NAION, but no histopathologic confirmation is available to date. ${ }^{2,} 64$ In the Ischemic Optic Neuropathy Decompression Trial (IONDT), ${ }^{48} 60 \%$ of NAION patients had at least one vasculopathic risk factor: $47 \%$ had hypertension, and $24 \%$ had diabetes. These numbers are very similar to another study that showed that hypertension was present in up to $49 \%$ and diabetes in up to $26 \%$ of patients with NAION. ${ }^{37}$ Any association with other vascular risk factors has been inconsistent. Smoking does not appear to be an independent risk factor. ${ }^{38}$ NAION has not been associated with ipsilateral carotid artery stenosis, and embolic AION is extremely rare. ${ }^{29}$

\section{III.3 Other factors}

Sleep apnea, generalized hypoperfusion, vasospasm, failure of autoregulation, severe anemia, and nocturnal hypotension are all potential, but unproven, contributory pathogenetic factors for NAION. ${ }^{2}$ An underlying mitochondrial abnormality has also been suggested. ${ }^{15}$ There is no gender predisposition for NAION. The mean age of onset is between 57 and 67 years, but NAION may occur at any age. NAION in patients less than 50 years of age is not uncommon, representing $23 \%$ of AION patients in a tertiary neuro-ophthalmic service. ${ }^{79}$ Except for giant cell arteritis, ocular and systemic risk factors and associated disorders are similar to those described in older AION patients. ${ }^{79}$ Drugs associated with the development of NAION include amiodarone ${ }^{75}$ and erectile dysfunction agents, ${ }^{62}$ but no definite causal relationship has been established.

\section{III.4 Animal models}

Two animal models have been developed, one using rodents, ${ }^{9}$ and one using primates. ${ }^{20}$ These use a novel photoembolic stroke model thought to be analogous to human AION. After infusing rose bengal, the optic nerve head is exposed to a laser that locally photoactivates the intravenous rose bengal. Within seconds, the photoactivated rose bengal then selectively damages the vascular endothelium of optic nerve head capillaries, resulting in thrombosis without associated thermal damage. The early histologic, electrophysiologic, and molecular changes associated with the isolated retinal ganglion cell axonal ischemia appear similar to those in human AION. This model permits detailed analyses of retinal and optic nerve changes after optic nerve infarction in animals. The rodent AION model has been used to show that estrogen treatment following AION resulted in no increased preservation of optic nerve structure. ${ }^{10}$ It has also been used to study AION-associated mechanisms of RGC death and the associated regional retinal changes. ${ }^{87}$ These animal models have been criticized as not reflecting true NAION, because the experimental ischemic lesions are induced primarily in the intraretinal region of the central retinal artery circulation, rather than in the deeper posterior ciliary artery circulation. ${ }^{39}$

\section{IV-Prognosis}

\section{IV.1 Visual prognosis in the affected eye}

In most cases of NAION, vision worsens progressively over 2 weeks and then remains stable over time. Some studies have shown recovery of 3 lines of acuity or better in $13 \% 87$ to $42.7 \% .^{35,76}$ The visual acuity does not appear to worsen once the disc edema has resolved. ${ }^{36}$ In the IONDT, which only included patients 50 years old or older, $35 \%$ of affected eyes had visual acuity better than 20/64--and 36\% worse than 20/200,--at 6 months. 
Of those who were randomized (20/64 vision or worse), 52\% had vision 20/200 or worse after 6 months. ${ }^{48}$ Other studies that included those with better visual acuity showed final visual acuity of 20/200 or worse in $31-42 \% .{ }^{12,14}$ In another study, younger patients (less than 50 years old) with AION had better visual acuity outcomes than those reported among the older patients from the IONDT, with $73 \%$ having visual acuity better than $20 / 64$, and $18 \%$ worse than $20 / 200 .{ }^{79}$

\section{IV.2 Risk of recurrence in the affected eye}

Recurrence of NAION in the affected eye occurs in less than $5 \%$ of cases. ${ }^{76}$ A likely explanation for the low rate of recurrence is that the atrophy of the optic nerve that follows NAION relieves crowding. ${ }^{40}$

\section{IV.3 Risk of involvement in the fellow eye}

In the IONDT approximately $15 \%$ of patients developed NAION in the fellow eye within 5 years. ${ }^{76}$ Presumably the other eye is exposed to the same risk factors for small vessel disease and also has the same structural vulnerability of a small cup to disc ratio. In the IONDT, risk of fellow eye involvement was related to poor baseline visual acuity in the first eye and to diabetes, but not to age, gender, smoking history, or aspirin use. ${ }^{76}$ In younger patients, the risk of fellow eye involvement seems to be higher than in older patients, with $35 \%$ involvement of the second eye within 7 months. ${ }^{79}$ Other retrospective studies have shown similar results. $^{7,12,14,59,83,85}$

\section{IV.4 Risk of other systemic vascular events}

There is no definite evidence that NAION is associated with an increased risk of subsequent myocardial or cerebral infarction, but no sufficiently large studies have been done. Given that $60 \%$ of NAION patients have at least one vascular risk factor, the risk of other systemic vascular events should still be considered, and vascular risk factors should be managed according to evidence- based guidelines. ${ }^{82}$

\section{V-Evidence-based classification scheme for studies of treatment in NAION}

A number of classification schemes have been developed that use empirically validated criteria to assess study strength. The classification we use is intended for use in studies seeking to answer therapeutic questions. ${ }^{28,68}$ The quality and risk of bias in a study is measured using a four-tiered classification of evidence scheme (Table 1). In this scheme, Class I studies are of high quality with low risk of bias. Class II studies are of moderate quality, with moderate risk of bias. Class III studies have a high risk of bias, and Class IV studies have a very high risk of bias. Randomized studies are considered the highest class of evidence. $^{28}$

As this review is of all publications on the treatment of NAION since 1960, many studies included were observational and predate the current era of evidence-based medicine. These include poorly documented case reports or series that were entirely anecdotal and that in most cases did not provide adequate information on the type of drugs used, the dose, the timing of administration, or outcome measures. These case reports and case series are all Class IV studies and inlclude the only studies on anticoagulation, retrobulbar vasodilators, and sub-Tenon vasodilators. Indeed, even most recent literature on the treatment of NAION consists of retrospective or prospective case series and anecdotal case reports (Table 2). The only class I trial for NAION is the Ischemic Optic Neuropathy Decompression Trial $(\text { IONDT })^{23,48}$--a negative trial for optic nerve sheath decompression surgery that nonetheless provided valuable natural history data. The utility and strength of studies can vary even within a class designation. In many circumstances, the only feasible study is a 
Class III or IV study, and some evidence may be better than none at all. ${ }^{28}$ In other situations, judgments regarding the efficacy of treatments have been made prematurely based on inadequate evidence.

\section{VI-Treatment of acute NAION}

Currently there is no generally accepted treatment for NAION, but a number of medical and surgical therapies have been proposed. Because the pathophysiology of NAION remains elusive, most are empirical and include a wide range of agents presumed to act on thrombosis, on the blood vessels, on the disc edema itself, or presumed to have a neuroprotective effect. Ischemic damage in NAION affects the optic nerve, and therefore the axons of the retinal ganglion cells. Some data from animal models suggest that the therapeutic window for NAION may be as long as two to three weeks. ${ }^{87}$ This is consistent with the common clinical finding of progressive visual loss over 2 weeks and the observation that most cases of NAION do not progress after one month. Visual dysfunction appears to plateau around the same time that disc edema is superseded by optic atrophy, but this does not necessarily mean that this is cause and effect. ${ }^{36}$ The IONDT specified a 2 week therapeutic window for surgical decompression, as did another recent study using steroids. ${ }^{41}$ The therapeutic window remains unclear; however, it seems reasonable that earlier intervention might lead to less axonal damage.

\section{VI.1 Mechanism 1: Action on thrombosis}

Although small vessel arterial occlusion has not been demonstrated in NAION, antithrombotic agents have been proposed as a treatment for NAION.

VI.1a Aspirin and other anti-platelet agents-Only one study evaluated the aspirin use. ${ }^{16}$ In this retrospective, case-control study 23 patients treated with aspirin regularly before and during the course of NAION were compared to 55 NAION patients who did not use aspirin. The visual outcome was similar in the two groups, both in terms of initial ( $\mathrm{p}=$ $0.36)$ and final $(\mathrm{p}=0.95)$ visual acuity. There was also no difference between patient and control groups for the initial $(p=0.60)$ and final $(p=0.41)$ mean deviation on automated perimetry. However, this study did not address the use of aspirin in acute NAION. It was retrospective, did not evaluate the administration of an anti-platelet agent within a therapeutic window, and did not specify the aspirin dose. ${ }^{16}$ There have been no studies investigating either clopidogrel or dipyridamole use.

VI.1b Anticoagulants-Apart from older, anecdotal case reports of modest amelioration of NAION in anti-coagulated patients, there does not seem to be any evidence for or against the use of anti-coagulation as an acute therapy. ${ }^{61,84}$

VI.1c Thrombolytics-We found only one case report of the use of thrombolysis in the treatment of acute NAION ${ }^{55}$ High dose urokinase in combination with stellate ganglion block was associated with good visual recovery in the affected eye and resolution of disc edema, leading the authors to suggest that this approach may improve optic nerve ischemia in the acute phase of AION. The weakness inherent in a single case report must be emphasized.

\section{VI.2 Mechanism 2: Action on blood vessels}

Vasodynamic factors invoked in the pathogenesis of NAION include generalized hypotension, vasospasm, failure of autoregulation, nocturnal hypotension and sleep apnea. This has led to studies of both systemic vasopressors and local and systemic vasodilators in 
NAION. Mechanical factors (such as cholesterol-related arteriosclerosis) are also potentially contributory.

VI.2a Pressor agents (norepinephrine)-The rationale for norepinephrine use is improvement of optic nerve head perfusion pressure. There is only one report of 3 patients receiving norepinephrine for acute NAION. ${ }^{58}$ In 2 of these cases, improvement in vision began within minutes after moderate hypertension was induced. The third patient showed no response in an eye with long-standing ION, but had prompt recovery of vision in the second eye early in the course. One patient could not be weaned off norepinephrine without recurrent visual loss. In another, controlled hypertensive therapy improved visual acuity to 20/30 during two separate recurrences of ischemic optic neuropathy. While the authors suggested that selected normotensive patients with ischemic optic neuropathy and retinal ischemia may benefit from controlled hypertensive therapy, this study does not specifically demonstrate any benefit of norepinephrine infusion. ${ }^{58}$ Furthermore, norepinephrine is a vasoconstricting agent that could potentially worsen ischemia.

VI.2b Vasodilators-Four case series of treatment with systemic and local vasodilators were published in the 1960s. ${ }^{13}, 18,27,31$ Twenty NAION patients were included in one study. ${ }^{27} 8$ were treated with systemic vasodilators (nicotinic acid and acetylcholine), 4 with both systemic vasodilators and systemic corticosteroids, 3 with retrobulbar injections of vasodilators, 1 with retrobulbar cortisone injection, and 4 received no treatment. The authors concluded that there was no benefit from any vasodilator, except in 2 cases where a systemic vasodilator was administered on the same day as the visual loss. Other reports confirm the apparent lack of effect of vasodilators. ${ }^{18,31}$ Another case series suggested that very early treatment with retro-bulbar or sub-Tenon injections of vasodilators and methylprednisolone every 2 or 3 days for a month may improve outcomes. ${ }^{13}$ These results do not support the routine use of systemic or sub-Tenon vasodilators in NAION.

Because vasodilators may cause systemic hypotension, implicated as a potential precipitating factor of NAION, we feel such strategies should be abandoned. Administration of the calcium channel blocker nifedipine reversed decreased optic nerve blood flow induced by intravenous and intravitreal infusions of endothelin- 1 in 12 healthy humans with no optic neuropathy. ${ }^{90}$

VI.2c Heparin-induced extracorporeal LDL/fibrinogen precipitation-Heparininduced extracorporeal LDL/fibrinogen precipitation (HELP) eliminates fibrinogen, LDL, cholesterol, and triglycerides from blood. It is thought that by decreasing levels of these substances, the rheologic situation is improved. In a prospective, randomized, controlled study over a period of 3 months, 40 patients with recent onset (less than two weeks) NAION were randomly assigned to either HELP or hemodilution therapy. ${ }^{33}$ There was no difference in visual acuity between the two groups ( $\mathrm{p}=0.48$ ). Visual acuity in the HELP group improved in $47.4 \%$, and remained stable in $52.6 \%$. In the hemodilution group visual acuity increased in $33.4 \%$, remained stable in $42.8 \%$, and worsened in $23.8 \%$. There was some mild, but significant $(\mathrm{p}<0.01)$, improvement in the calculated mean deviation of visual fields in the HELP group as compared to the hemodilution group. ${ }^{33}$

\section{VI.3 Mechanism 3: Action on optic disc edema}

Because disc edema may contribute to axonal damage in NAION, a number of medical and surgical interventions aim to shorten the duration of disc edema. Optic disc edema is by definition present in NAION and characteristically persists a few weeks. A recent study showed that the median time (25-75th percentile) to spontaneous resolution of optic disc edema from onset of visual loss was 7.9 (5.8-11.4) weeks. ${ }^{36}$ Resolution time was longer in 
diabetics than in non-diabetics $(\mathrm{p}=0.003)$, and multi-factor analysis showed that worse initial visual field defects $(\mathrm{p}<0.0001)$ and acuity $(\mathrm{p}=0.04)$ were associated with faster resolution. ${ }^{36}$ There is, however, no evidence that decreasing the duration of disc edema improves visual outcome.

VI.3a Systemic steroids-The rationale for the use of steroids in NAION comes from a study from the late 1960's that postulated that steroids would decrease capillary permeability, thereby inducing faster resolution of disc edema. ${ }^{26}$ This, in turn, would reduce compression of capillaries in the optic nerve head and improve blood flow, restoring the function of surviving, but non-functioning, ischemic axons. Improvement in visual acuity occurred in 11 of 13 (85\%) patients treated with systemic steroids (60 mg prednisone daily), compared to 5 of 11 patients (45\%) not treated. In 1974, Hayreh reported improvement in visual acuity in $75 \%$ of 8 treated NAION eyes, compared to $17 \%$ of 6 untreated eyes. ${ }^{42}$ Neither study was randomized, and it is difficult to draw conclusions from so few subjects. There have been no studies using high dose intravenous steroids in NAION and no randomized, controlled studies investigating the role of oral corticosteroid therapy.

Hayreh recently reported 613 consecutive patients seen between 1973 and $2000 .{ }^{41} 312$ patients voluntarily opted for systemic steroid therapy and 301 for no treatment. Of those who chose steroid therapy, 236 were treated within 2 weeks of onset. Patients were initially given $80 \mathrm{mg}$ of prednisone daily for 2 weeks, followed by a taper every 5 days to $70 \mathrm{mg}, 60$ $\mathrm{mg}$, and then decreasing the dose by $5 \mathrm{mg}$ every 5 days to $40 \mathrm{mg}$ until the optic disc edema was no longer present. Prednisone was rapidly tapered off completely following resolution of disc edema. In those treated with steroid therapy within 2 weeks, the median time to optic disc edema resolution was 6.8 weeks, compared to 8.2 weeks in untreated cases $(\mathrm{p}<0.0001) .36$

Visual outcome in the two groups was compared with a median follow-up of 3.8 years. At 6 months, eyes with initial visual acuity 20/70 or worse treated within 2 weeks of onset had visual acuity improvement in $69.8 \%$, compared to $40.5 \%$ in the untreated group ( $\mathrm{p}=0.001$ ). Comparison of visual field defects at 6 months found improvement in $40.1 \%$ of the treated group, compared to $24.5 \%$ of the untreated group $(\mathrm{p}=0.005)$. In both the treated and untreated groups, the visual acuity and visual fields kept improving up to about 6 months, and very little thereafter. Hayreh et al concluded that early treatment of NAION with prednisone $80 \mathrm{mg}$ improved visual acuity $(\mathrm{p}=0.001)$ and visual field $(\mathrm{p}=0.005){ }^{41}$ Their patients were not randomized, and the untreated group had more vascular risk factors, , making it difficult to interpret their results. In addition, the earlier resolution of disc edema seen in the treated group is particularly subject to selection bias, since diabetics were much less likely to be treated, and the authors' own data demonstrate that edema persists longer in diabetics. ${ }^{36}$

VI.3b Intravitreal triamcinolone-The rationale for intravitreal steroids is the same as for systemic steroids. Intravitreal triamcinolone acetonide is routinely used to treat retinal edema in conditions such as diabetic retinopathy or retinal vein occlusion and has been tried in a few patients with NAION. ${ }^{54}$ Four mg of intravitreal triamcinolone acetonide was administered to 4 eyes of 4 patients with severe visual loss (20/200 or worse) within 22 days of onset. The visual outcome was compared to 6 consecutive patients with NAION who received no treatment. All patients completed at least 9 months of follow-up. In the treated group, the mean improvement in visual acuity was 6.2 Snellen lines at the final visit. Optic disc swelling and leakage markedly decreased by the first post injection week and had disappeared by 3 weeks in all eyes. In the non-treated group, the mean improvement in visual acuity was 1.3 lines at the final visit, and optic disc swelling resolved between 4 to 12 weeks. The authors concluded that intravitreal triamcinolone acetonide provided better 
recovery of visual acuity and more rapid resolution of optic disc swelling, but no visual field improvement was seen in this small sample. ${ }^{54}$

It was subsequently suggested that changes in fixation strategy may explain why the visual acuity improved, while the visual fields did not. ${ }^{43}$ Although intravitreal triamcinolone acetonide has the advantage of fewer systemic side effects, it often results in persistent increased intraocular pressure that may worsen optic nerve damage. ${ }^{43}$

Another recent case series reported intravitreal triamcinolone acetonide $4 \mathrm{mg}$ injection in four patients with acute (4 to 10 days after visual loss) NAION. ${ }^{95}$. All four patients experienced some visual improvement. No complications related were observed during the following 3 months. The limited 3 month follow up should be considered in interpreting these results, since $40 \%$ of patients experience intraocular pressure rises, which may not occur until more than 24 months after injection. ${ }^{81}$

VI.3c Intravitreal anti-vascular endothelial growth factor agents-Vascular endothelial growth factor (VEGF) is a signalling protein that stimulates angiogenesis and increases microvascular permeability. Anti-VEGF agents such as bevacizumab and ranibizumab inhibit the signalling of VEGF, thereby potentially reducing the vasogenic edema that manifests as optic disc edema. Anti-VEGF agents are routinely used in neovascular macular degeneration and in macular edema associated with other retinal vascular disorders.

Intravitreal bevacizumab $(1.25 \mathrm{mg} / 0.05 \mathrm{~mL})$ was given to one patient with severe visual loss and persistent disc edema from acute NAION 3 weeks after visual loss. ${ }^{11}$ Nine days later, there was marked reduction in the swelling. Visual acuity improved from count fingers vision to 20/70; the visual field also improved. At 8 weeks post injection, modest inferior and superior disc swelling remained. ${ }^{11}$

VI.3d Optic nerve decompression surgery-Optic nerve sheath decompression may be beneficial for papilledema. It was thought, therefore, that reducing the cerebrospinal fluid pressure within the perineural subarachnoid space could relieve the "compartment syndrome", improve local blood flow, and enhance axoplasmic flow within the damaged axons in NAION. ${ }^{2}$

The Ischemic Optic Neuropathy Decompression Trial (IONDT) was a randomized, singleblind, multicenter trial sponsored by the National Eye Institute to assess the safety and efficacy of optic nerve decompression surgery in patients with NAION. ${ }^{48}$ The IONDT ceased recruitment in 1994 on the recommendation of its Data and Safety Monitoring Committee. One hundred and nineteen patients had been assigned to surgery within two weeks of onset, and 125 were untreated. Visual acuity improved at least 3 Snellen lines in $32.6 \%$ of the treated group compared to $42.7 \%$ in the untreated group. Even more concerning was that $23.9 \%$ of treated patients worsened by 3 Snellen lines or more, compared to $12.4 \%$ of untreated patients. The IONDT found that optic nerve decompression surgery for NAION is not just ineffective, but may be harmful. Analysis of data from patients enrolled in the IONDT at 24 months of follow-up confirmed that there was no benefit from optic nerve decompression surgery. ${ }^{49}$ It is worth mentioning that the IONDT was stimulated by reports of visual improvement in progressive NAION after optic nerve sheath fenestration, and the IONDT was underpowered to assess this subgroup of NAION. ${ }^{67}$

VI.3e Transvitreal optic neurotomy-In an attempt to decompress the prelaminar and laminar regions of the optic nerve head and address the "compartment syndrome", 8 NAION patients underwent transvitreal optic neurotomy. ${ }^{88}$ This involves a trans-vitreal stab incision 
at the nasal margin of the optic disc to widen the physiologically small scleral canal, hopefully relieving pressure on the edematous and ischemic optic nerve. 16 patients with visual acuity less than 20/200 were enrolled within 6 weeks of onset; 8 subjects were randomized to the procedure, while 8 were observed. Visual acuity improved by more than 2 Snellen lines in 6 eyes $(75 \%)$ in the neurotomy group and in 2 eyes $(25 \%)$ in the observation group at 6 months follow-up. Visual fields improved in 6 eyes, deteriorated in 1 eye, and remained unchanged in 1 eye in the treatment group.I In the observation group, visual fields improved in 1 eye, remained stable in 5, and deteriorated in $2 .{ }^{88}$ Because this was a small study with delayed treatment, and with only moderate visual improvement, the results should be interpreted with caution.

VI.3f Vitrectomy and release of epipapillary vitreous traction-In some cases of NAION and partial posterior vitreous detachment, elevation of the optic nerve head from persistent epipapillary vitreous traction may lead to impairment of both the microvascular circulation and of axoplasmic flow, resulting in dysfunction and edema of the optic disc. Eyes with small, crowded discs may be more vulnerable to the distorting forces of vitreous traction. Surgical release of epipapillary vitreous traction has recently been tried in 16 cases with small discs and partial posterior vitreous detachment demonstrated on ocular coherence tomography. Pars plana vitrectomy with removal of epipapillary adhesions was performed within 1 month of the onset of visual symptoms of NAION. ${ }^{72}$ In 15 patients $(93.7 \%$ ) visual acuity improved. Nine patients (56\%) had 3 lines or more of visual improvement. While vitrectomy cannot be considered as a routine treatment option, this study supports a possible role for vitreous traction in NAION.

Others have questioned these results, ${ }^{63}$ asserting that the OCT configuration described as "partial posterior detachment" in the study actually represents the normal vitreous attachment to the optic disc in the older patient, and the separation from the retina may represent early vitreous liquefaction rather than traction on the optic disc. Their OCT data argues against traction as a major contributor to the pathophysiology of NAION. ${ }^{63}$

\section{VI.4 Mechanism 4: Action on limiting neuronal or axonal injury}

In NAION, the primary injury is at the level of the optic nerve, affecting the axons of the retinal ganglion cells. The metabolism of the retinal ganglion cells is affected after axonal damage, resulting in secondary excitotoxicity and cell death. Neuronal death could potentially be blocked, and a longer therapeutic window may exist for NAION than in conditions that directly affect the retinal ganglion cells, such as central retinal artery occlusion. The failure of neurotrophic factors, particularly brain-derived neurotrophic factor (BDNF), to reach the retinal ganglion cell through interrupted retrograde axonal transport, may trigger apoptosis. Besides neurotrophic factor deprivation and excitotoxicity, other effects of axonal injury may include oxidative stress, calcium influx, and mitochondrial failure. Once the retinal ganglion cell dies, there is loss of the axon via Wallerian degeneration. ${ }^{2,64}$ A number of neuroprotective strategies aimed at both improving neuronal survival and limiting axonal injury have been proposed in NAION.

VI.4a Diphenylhydantoin-Because diphenylhydantoin improves conduction in hypoxic neurons, one small, randomized study evaluated its effect on chronic NAION. ${ }^{24} 15$ patients were randomized to either placebo or to $300 \mathrm{mg}$ per day of oral diphenylhydantoin at least 3 months after the onset of acute visual loss (to allow for spontaneous improvement). After 3 months, patients receiving placebo were changed to diphenylhydantoin for a further 3 months. Four additional patients were given diphenylhydantoin alone for 6 months. Participants were examined at one month intervals, and there was no improvement in either visual acuity or visual fields. ${ }^{24}$ 
VI.4b Levodopa-The rationale for the use of levodopa in NAION has been a subject of debate. ${ }^{6,43}$ Studies in the literature on decreased brain and retinal dopamine levels in amblyopia and Parkinson's disease, and conjecture about the potential of levodopa to enhance neuronal plasticity and alter the metabolic milieu of the retina, led to investigation of levodopa as a neuroprotective agent in NAION ${ }^{50}$ Additionally, it was recently suggested that any benefit of levodopa therapy in NAION may actually arise from the ability of dopamine receptor agonists to inhibit VEGF-mediated vascular permeability. ${ }^{6,} 32$

A nonrandomized, retrospective, comparative trial involving 37 patients studied the effect of levodopa in patients treated within 45 days of onset of NAION. ${ }^{52} 18$ NAION patients were administered a capsule of $100 \mathrm{mg}$ levodopa/25 $\mathrm{mg}$ carbidopa three times daily for 3 weeks, while 19 control patients were untreated. Ten of the 13 patients (76.9\%) in the levodopa group who had visual acuities of 20/40 or worse at baseline improved by 6 months, whereas none of the 18 patients had worsened. In contrast, 3 of 10 control patients (30\%) with 20/40 visual acuity or worse at baseline had improved visual acuity at 6 months, and 3 of 19 control patients $(16.3 \%)$ had worsened. The authors concluded that patients treated with levodopa were more likely to experience improvement, and less likely to have worsened,. This study, however, has been criticized for design and methodology flaws, and for a weak rationale for the use of levodopa treatment in NAION. ${ }^{6,44}$

VI.4c Topical brimonidine tartrate-Alpha-adrenergic agonists have increase the levels of basic fibroblast growth factor and brain derived neurotrophic factor and have demonstrated some neuroprotective effect on experimental retinal and optic nerve injury. ${ }^{19,78,91,92,94,96}$ Therefore, topical brimonidine tartrate $0.2 \%$ was investigated in NAION. A multicenter randomized clinical trial was organized in 2000 in the United States (NPION trial), but was not completed because of difficulties with recruitment within the 48 hour therapeutic window. ${ }^{1}$ A similar study with a 7 day window (BRAION) trial was performed in Europe. ${ }^{93}$ Thirty-six patients with first eye involvement and typical signs of NAION were randomized to treatment with either brimonidine $0.2 \%$ or placebo. Poor recruitment was also a problem despite the extended 7 day window, and the study was stopped when an interim analysis showed it was unlikely to be completed within a practical time frame. No significant advantage for patients receiving brimonidine $0.2 \%$ was shown. ${ }^{93}$ In addition, this therapy was further questioned when another retrospective study found a trend to a worse visual outcome in 14 NAION patients treated with brimonidine tartrate $0.2 \%$ up to four times daily within 14 days of onset of visual loss. ${ }^{25}$

VI.4d Hyperbaric oxygen-Hyperbaric oxygen therapy elevates the dissolved oxygen content of blood, thereby providing increased tissue oxygen and potentially reducing damage in injured axons. The effectiveness of hyperbaric oxygen in 20 NAION patients between 3 and 20 days of onset of visual loss was evaluated. ${ }^{4}$ Patients received hyperbaric oxygen in two 90-minute inhalation sessions per day for ten days (100\% oxygen, 2.0 absolute atmospheres of pressure). Changes in mean visual acuity and mean sensitivity loss were compared with those of 27 untreated control patients with acute NAION. There was no improvement in visual acuity or visual field even in the subgroup treated within 9 days of onset of symptoms.

VI.4e Transcorneal electrical stimulation-Studies in Japan have shown that, in adult rats, there is significantly increased survival of the retinal ganglion cells if electrical stimulation is applied to the optic nerve just after axotomy. ${ }^{74}$ Transcorneal electrical stimulation (TES) with a contact lens electrode has also been shown to stimulate the retinal ganglion cells and/or their axons, ${ }^{71}$ raising the question whether TES could improve the visual function of patients with NAION or traumatic optic neuropathy. Eight consecutive 
patients with optic neuropathies were studied. ${ }^{30}$ Transcorneal electrical stimulation was applied once to 3 eyes with NAION and to 5 eyes with traumatic optic neuropathy. The interval between the visual loss and the application of TES treatment was 4 to 24 months (median 6 months) in the NAION group. Some improvement in visual acuity occurred in 2 NAION patients and in 4 traumatic optic neuropathy patients. ${ }^{30}$ This study does not prove that the treatment is beneficial since the therapy was delayed, and there is no way to determine whether the visual improvement is anything other than spontaneous.

\section{VII-Secondary prevention (prevention of AION in the fellow eye)}

The goals of secondary prevention are to prevent recurrent NAION, to reduce the risk of development of NAION in the fellow eye, and to potentially prevent systemic vascular disease. Because NAION is an ischemic disorder occurring more often after the age of 50 in patients with cardiovascular risk factors, most practitioners recommend aggressive risk factor management and anti-platelet therapy.

\section{VII.1 Aspirin and other anti-platelet agents}

Only aspirin has been evaluated in the prevention of NAION in the fellow eye. Four retrospective studies (Table 2) have been published. ${ }^{7,59,76,83}$ The largest retrospective study included 431 patients, 153 of whom had received aspirin following the development of unilateral NAION and 278 had not. ${ }^{7}$ By 5 years the cumulative probability of NAION in the fellow eye was $17 \%$ in the aspirin group and $20 \%$ in the no aspirin group, failing to show any long term benefit of aspirin in reducing the risk of NAION in the fellow eye. ${ }^{7}$

In another study, ${ }^{59}$ the records of 100 NAION patients were retrospectively reviewed. 33 patients who had second eye NAION were compared to those with unilateral NAION who had been followed for a minimum of 2 years. Aspirin $(65-1,300 \mathrm{mg})$ taken two or more times per week decreased the incidence $(17.5 \%$ vs. $53.5 \%)$ and relative risk $(\mathrm{RR}=0.44, \mathrm{p}=$ 0.0002 ) of fellow eye NAION regardless of vascular risk factors, suggesting that aspirin may be an effective means of reducing sequential NAION. ${ }^{59}$

A smaller study ${ }^{83}$ showed similar results. Fellow eye involvement was noted in 8 of 16 patients (50\%) who did not receive aspirin, in 3 of 8 patients (38\%) who received $100 \mathrm{mg} /$ day aspirin, and in only 5 of 28 patients (18\%) who received aspirin $325 \mathrm{mg} /$ day, suggesting that aspirin at $325 \mathrm{mg} /$ day may be effective in reducing sequential involvement with NAION.

Although the IONDT was a prospective trial designed to evaluate the benefit of optic nerve sheath decompression, data on the use of aspirin was retrospectively obtained on 326 patients. 87 patients reported taking aspirin regularly for at least one month prior to the onset of their symptoms, and $20 \%$ of these developed NAION in the fellow eye, whereas $13 \%$ of 237 non-aspirin treated patients developed NAION in the fellow eye. This suggested that aspirin does not reduce fellow eye NAION occurrence. ${ }^{76}$

These studies are retrospective and do not provide sufficient evidence to support aspirin therapy as secondary prevention in NAION. Studies showing a reduced rate of fellow eye involvement with aspirin were based on an untreated baseline rate of fellow eye involvement of $53.5 \%$ in one, ${ }^{59}$ and $50 \%$ in the other, ${ }^{83}$ much higher than the estimated $15 \%$-year rate documented in larger studies. ${ }^{7,76}$. The follow-up duration varied, but this may be the reason for the contrast with larger studies. However, these studies show no evidence of increased risk of NAION in aspirin users. In addition, it has been well shown that aspirin prevents of ischemic events, ${ }^{83}$ and given the association of cardiovascular risk factors and systemic 
vasculopathy with NAION, it seems reasonable to recommend aspirin therapy to those patients who have other risk factors.

\section{VII.2 Retinal laser photocoagulation}

Based on the postulated role of crowding of optic nerve head axons in the development of NAION, some authors have discussed the option of decompressing the at risk optic nerve in the fellow eye by using retinal laser photocoagulation to induce axonal dropout and optic atrophy. ${ }^{17}$ However, destruction of the peripheral retina produces visual field loss, and it does not seem reasonable to propose such aggressive treatment in a normal eye.

\section{VII.3 Correction of other factors}

Both diabetes ${ }^{37}$ and sleep apnea ${ }^{73}$ have been associated with NAION, and diabetes has been associated with increased risk of NAION in the fellow eye. ${ }^{77}$ Optimal control of diabetes and treatment of sleep apnea is recommended; however, 3 patients with sleep apnea developed NAION while being treated with continuous positive airway pressure (CPAP) for 4 months to 6 years prior to symptom onset. ${ }^{8}$ In this series, CPAP did not prevent the development of NAION. Larger studies are needed to determine the benefit of CPAP in preventing NAION in patients with sleep apnea.

Other modifiable risk factors have been less consistently associated with NAION, including hypertension, hypercholesterolemia, and anemia. ${ }^{17,}{ }^{37}$ Hypercholesterolemia is a risk factor for NAION in patients aged 50 years or younger, and NAION may be the first manifestation of elevated serum lipids. ${ }^{22}$ It seems reasonable to treat these identifiable risk factors to decrease risk of systemic vascular disease. Smoking was not found to be an independent risk factor in one large cohort study, ${ }^{38}$ but contributes to poor overall cardiovascular health and should be discontinued. Whether drugs such as erectile dysfunction drugs should be discontinued or not remains controversial and needs to be discussed on a case by case basis. ${ }^{45,62}$ Amiodarone has been associated with the occurrence of an optic neuropathy resembling NAION. Although this association remains controversial, it is reasonable to discontinue amiodarone in this clinical setting with the cardiologist's agreement. ${ }^{45,75}$ One study suggested that nocturnal arterial hypotension may be a risk factor for NAION. ${ }^{46}$ However, another study showed no significant difference in nocturnal hypotension between NAION patients and controls matched for age, gender, medical condition, and medication. ${ }^{60}$ Whether or not nocturnal arterial hypotension is a contributory factor in NAION remains uncertain.

As emphasized by the IONDT, the apparent higher incidence of NAION found on waking could also be explained by the fact that $1 / 3$ of NAION may occur during the $1 / 3$ of the day spent on average asleep, making it appear as if there is a greater occurrence on waking, when the actual onset of NAION could have been during the period of sleep. Nevertheless, some physicians recommend that NAION patients with arterial hypertension take antihypertensive medication in the morning rather than at night.

\section{VIII - Visual Rehabilitation}

Unfortunately, more than $50 \%$ of NAION patients are left with visual acuity worse than $20 / 200{ }^{49}$ with constricted visual fields. ${ }^{86}$ In these cases, and particularly in those with bilateral involvement, prompt low vision consultation is essential. Even patients with relatively preserved central visual acuity are disabled because of their visual field loss. A recent multicenter, randomized controlled trial showed that patients with age-related macular degeneration and vision loss worse than 20/100 had a better functional outcome when low vision services were offered as early as possible after visual impairment was 
diagnosed. ${ }^{89}$ It is likely that the same results would have been observed with NAION patients.

Vision restoration therapy (VRT) uses a computer device to stimulate areas of residual vision in patients with visual field defects. It may improve visual function by stimulating eccentric fixation, improving attention, promoting saccadic eye movement, or enhancing neuroplasticity. A recent randomized controlled double-blind pilot trial to evaluate the effects of VRT on the visual function of 10 NAION patients suggested some benefit on visual function; ${ }^{53}$ However, VRT remains controversial for patients with homonymous hemianopia, and so far there is very little evidence to support the use of VRT as part of low vision interventions offered to patients with optic neuropathies.

\section{IX - Conclusion}

NAION remains frustrating for clinicians and often devastating for patients. The pathophysiology remains unclear, and it is uncertain whether any treatment will be effective for NAION. Many therapies have been inadequately studied. Despite its limitations, the NAION animal model will allow preclinical evaluation of neuroprotective agents and may be important in suggesting future approaches to treatment. The role of oral steroids remains controversial, and the literature regarding prevention of sequential NAION is contradictory. Treatment of vascular risk factors and anti-platelet therapy, however, both have an established role in the prevention of cerebral and myocardial infarction and should be considered in NAION despite the lack of class I evidence.

\section{X- Method of Literature Search}

For this review we conducted a Medline and Pubmed search of the medical literature for the period between 1960 and 2009 using the following key words: nonarteritic anterior ischemic optic neuropathy, treatment, pathogenesis, Ischemic Optic Neuropathy Decompression Trial (IONDT). Reference lists from the selected articles were used to obtain further relevant articles not included in the electronic database. Only articles pertinent to the treatment of NAION were included.

\section{Acknowledgments}

This study was supported in part by a departmental grant (Department of Ophthalmology) from Research to Prevent Blindness, Inc, New York, New York, and by core grant P30-EY06360 (Department of Ophthalmology) from the National Institute of Health, Bethesda, Maryland. Dr Newman is a recipient of a Research to Prevent Blindness Lew R. Wasserman Merit Award.

\section{References}

1. Arnold, AC. Ischemic optic neuropathy. In: Miller, NR.; Newman, NJ.; Biousse, V., et al., editors. Clinical Neuro-Ophthalmology. 6. Vol. 1. Philadelphia: Lippincott, Williams \& Wilkins; 2005. p. 349-384.

2. Arnold AC. Pathogenesis of nonarteritic anterior ischemic optic neuropathy. J Neuro-Ophthalmol. 2003; 23(2):157-63.

3. Arnold AC, Levin LA. Treatment of ischemic optic neuropathy. Semin Ophthalmol. 2002; 17(1): 39-46. [PubMed: 15513455]

4. Arnold AC, Hepler RS, Lieber M, et al. Hyperbaric oxygen therapy for nonarteritic anterior ischemic optic neuropathy. Am J Ophthalmol. 1996 Oct; 122(4):535-41. [PubMed: 8862051]

5. Beck RW, Servais GE, Hayreh SS. Anterior ischemic optic neuropathy. IX. Cup-to-disc ratio and its role in pathogenesis. Ophthalmology. 1987; 94(11):1503-8. [PubMed: 3684223]

6. Beck RW, Ferris FL. Does levodopa improve visual function in NAION? Ophthalmology. 2000; 107(8):1431-3. [PubMed: 10919877] 
7. Beck RW, Hayreh SS, Podhajsky PA, et al. Aspirin therapy in nonarteritic anterior ischemic optic neuropathy. Am J Ophthalmol. 1997; 123(2):212-7. [PubMed: 9186127]

8. Behbehani R, Mathews MK, Sergott RC, et al. Nonarteritic anterior ischemic optic neuropathy in patients with sleep apnea while being treated with continuous positive airway pressure. Am J Ophthalmol. 2005 Mar; 139(3):518-21. [PubMed: 15767063]

9. Bernstein SL, Guo Y, Kelman SE, et al. Functional and cellular responses in a novel rodent model of anterior ischemic optic neuropathy. Invest Ophthalmol Vis Sci. 2003; 44(10):4153-62. [PubMed: 14507856]

10. Bernstein SL, Mehrabyan Z, Guo Y, Moianie N. Estrogen is not neuroprotective in a rodent model of optic nerve stroke. Mol Vis. 2007; 13:1920-5. [PubMed: 17982415]

11. Bennett JL, Thomas S, Olson JL, et al. Treatment of nonarteritic anterior ischemic optic neuropathy with intravitreal bevacizumab. J Neuroophthalmol. 2007; 27(3):238-40. [PubMed: 17895825]

12. Boghen DR, Glaser JS. Ischemic optic neuropathy: the clinical profile and natural history. Brain. 1975; 98(4):689-708. [PubMed: 1218373]

13. Bonamour G. Apropos de pseudo-papillites vasculaire. Bull Soc Ophtalmol Fr. 1966; 79:846. [PubMed: 5976443]

14. Boone MI, Massry GG, Frankel RA, et al. Visual outcome in bilateral nonarteritic anterior ischemic opti neuropathy. Ophthalmol. 1996; 103(8):1223-8.

15. Bosley TM, Abu-Amero KK, Ozand PT. Mitochondrial DNA changes in nonarteritic ischemic optic neuropathy. Neurology. 2004; 63(7):1305-8. [PubMed: 15477560]

16. Botelho PJ, Johnson LN, Arnold AC. The effect of aspirin on the visual outcome of nonarteritic anterior ischemic optic neuropathy. Am J Ophthalmol. 1996; 121(4):450-1. [PubMed: 8604744]

17. Burde RM. Optic disc risk factors for nonarteritic anterior ischemic optic neuropathy. Am J Ophthalmol. 1993; 116(6):759-64. [PubMed: 8250081]

18. Calmettes L, Deodati F, Bechac G. Pseudo-papillite vasculaire. Rev Oto Neuro Ophtal. 1963; 35:64-5.

19. Chao HM, Chidlow G, Melena J, Wood, et al. An investigation into the potential mechanisms underlying the neuroprotective effect of clonidine in the retina. Brain Res. 2000; 877(1):47-57. [PubMed: 10980242]

20. Chen CS, Johnson MA, Flower RA, et al. A Primate Model of Nonarteritic Anterior Ischemic Optic Neuropathy (pNAION). Invest Ophthalmol Vis Sci. 2008; 49(7):2985-92. [PubMed: 18326695]

21. Chi T, Rotch R, Stickler D, et al. Racial differences in optic nerve head parameters. Arch Ophthalmol. 1989; 107(6):836-9. [PubMed: 2730402]

22. Deramo VA, Sergott RC, Augsburger JJ, et al. Ischemic optic neuropathy as the first manifestation of elevated cholesterol in young patients. Ophthalmol. 2003; 110(5):1041-6.

23. Dickersin K, Manheimer E, Li T. Surgery for nonarteritic anterior ischemic optic neuropathy. Cochrane Database of Systematic Reviews. 2006; 1:CD001538. Art. No. 10.1002/14651858.CD001538.pub2 [PubMed: 16437435]

24. Ellenberger C Jr, Burde RM, Keltner JL. Acute optic neuropathy. Treatment with diphenylhydantoin. Arch Ophthalmol. 1974; 91(6):435-8. [PubMed: 4827427]

25. Fazzone HE, Kupersmith MJ, Leibmann J. Does topical brimonidine tartrate help NAION? Br J Ophthalmol. 2003; 87(9):1193-4. [PubMed: 12928304]

26. Foulds WS. Visual disturbances in systemic disorders: optic neuropathy and systemic disease. Trans Ophthalmol Soc UK. 1970; 89:125-46. [PubMed: 5276645]

27. Francois J, Verriest G, Neetens A, et al. (1962) Pseudo-papillites vasculaire. Ann Ocul (Paris). 1962; 195:830-85. [PubMed: 13963101]

28. French J, Gronseth G. Lost in a jungle of evidence: we need a compass. Neurology. 2008 Nov 11; 71(20):1634-8. [PubMed: 19001254]

29. Fry CL, Carter JE, Kanter MC, et al. Anterior ischemic optic neuropathy is not associated with carotid artery atherosclerosis. Stroke. 1993; 24(4):539-42. [PubMed: 8465359] 
30. Fujikado T, Morimoto T, Matsushita K, et al. Effect of transcorneal electrical stimulation in patients with nonarteritic ischemic optic neuropathy or traumatic optic neuropathy. Jpn J Ophthalmol. 2006; 50(3):266-73. [PubMed: 16767383]

31. Georgiades G, Konstas P, Stangos N. Reflexions issues de l'etude de nombreaux cas de pseudopapillite vasculaire. Bull Soc Ophtal Fr. 1966; 79:506-36.

32. Gomez R, Gonzalez-Izquierdo M, Zimmermann RC, et al. Lowdose dopamine agonist administration blocks vascular endothelial growth factor (VEGF)-mediated vascular hyperpermeability without altering VEGF receptor 2-dependent luteal angiogenesis in a rat ovarian hyperstimulation model. Endocrinology. 2006; 147(11):5400-11. [PubMed: 16901966]

33. Haas A, Walzl M, Jesenik F, et al. Application of HELP in nonarteritic anterior ischemic optic neuropathy: a prospective, randomized, controlled study. Graefes Arch Clin Exp Ophthalmol. 1997; 235(1):14-9. [PubMed: 9034837]

34. Hattenhauer MG, Leavitt JA, Hodge DO, et al. Incidence of nonarteritic anterior ischemic optic neuropathy. Am J Ophthalmol. 1997; 123(3):103-7. [PubMed: 9186104]

35. Hayreh SS. Ischemic optic neuropathy. Prog Retin Eye Res. 2008; 27(6) Epub ahead of print.

36. Hayreh SS, Zimmerman MB. Optic disc edema in non-arteritic anterior ischemic optic neuropathy. Graefes Arch Clin Exp Ophthalmol. 2007; 245(8):1107-21. [PubMed: 17219123]

37. Hayreh SS, Joos KM, Podhajsky PA, Long CR. Systemic diseases associated with nonarteritic anterior ischemic optic neuropathy. Am J Ophthalmol. 1994; 118(6):766-80. [PubMed: 7977604]

38. Hayreh SS, Jonas JB, Zimmerman MB. Nonarteritic anterior ischemic optic neuropathy and tobacco smoking. Ophthalmol. 2007; 114(4):804-9.

39. Hayreh SS. Animal model for nonarteritic anterior ischemic optic neuropathy. J Neuroophthalmol. 2008; 28(1):79-80. author reply 80-1. [PubMed: 18347469]

40. Hayreh SS. Ipsilateral recurrence of non-arteritic anterior ischemic optic neuropathy. Am J Ophthalmol. 2001; 132(5):734-42. [PubMed: 11704035]

41. Hayreh SS, Zimmerman MB. Non-arteritic anterior ischemic optic neuropathy: role of systemic corticosteroid therapy. Graefes Arch Clin Exp Ophthalmol. 2008 Jul; 246(7):1029-46. [PubMed: 18404273]

42. Hayreh SS. Anterior ischemic optic neuropathy. III. Treatment, prophylaxis and differential diagnosis. Br J Ophthalmol. 1974; 58(12):981-9. [PubMed: 4376417]

43. Hayreh SS. Intravitreal triamcinolone for nonarteritic anterior ischemic optic neuropathy. J NeuroOphthalmol. 2008; 28(1):77-8.

44. Hayreh SS. Does Levodopa improve visual function in NAION? Ophthalmology. 2000; 107(8): 1434-5. [PubMed: 10919878]

45. Hayreh SS. Amiodarone, erectile dysfunction drugs, and non-arteritic ischemic optic neuropathy. J Neurol-Ophthalmol. 2006; 26(2):154-5.

46. Hayreh SS, Zimmerman MB, Podhajsky P, et al. Nocturnal arterial hypotension and its role in optic nerve head and ocular ischemic disorders. Am J Ophthalmol. 1994; 117(5):603-24. [PubMed: 8172267]

47. Hedges TR 3rd, Vuong LN, Gonzalez-Garcia AO, et al. Subretinal fluid from anterior ischemic optic neuropathy demonstrated by optical coherence tomography. Arch Ophthalmol. 2008 Jun; 126(6):812-5. [PubMed: 18541844]

48. Ischemic Optic Neuropathy Decompression Trial Research Group. Optic nerve decompression surgery for nonarteritic anterior ischemic optic neuropathy (NAION) is not effective and may be harmful. The Ischemic Optic Neuropathy Decompression Trial Research Group. JAMA. 1995; 273(8):625-32. [PubMed: 7844872]

49. Ischemic Optic Neuropathy Decompression Trial Research Group. Characteristics of patients with non-arteritic anterior ischemic optic neuropathy eligible for the Ischemic Optic Neuropathy Decompression Trial. Arch Ophthalmol. 1996; 114(11):1366-74. [PubMed: 8906027]

50. Ischemic Optic Neuropathy Decompression Trial Research Group. Ischemic optic neuropathy decompression trial: twenty-four month update. Arch Ophthalmol. 2000; 118(6):793-8. [PubMed: 10865316] 
51. Jacobson DM, Vierkant RA, Belongia EA. Nonarteritic anterior ischemic optic neuropathy: a casecontrol study of potential risk factors. Arch Ophthalmol. 1997; 115(11):1403-7. [PubMed: 9366670]

52. Johnson LN, Guy ME, Krohel GB, et al. Levodopa may improve vision loss in recent-onset, nonarteritic anterior ischemic optic neuropathy. Ophthalmology. 2000; 107(3):521-6. [PubMed: 10711891]

53. Jung CS, Bruce B, Newman NJ, et al. Visual function in anterior ischemic optic neuropathy: Effect of vision restoration therapy - a pilot study. J Neurol Sci. 2008; 268(1-2):145-9. [PubMed: 18207164]

54. Kaderli B, Avci R, Yucel A, et al. Intravitreal triamcinolone improves recovery of visual acuity in nonarteritic anterior ischemic optic neuropathy. J Neuroophthalmol. 2007; 27(3):164-8. [PubMed: 17895814]

55. Kajiwara K, Tsubota K, Hara Y. High dose urokinase thrombolysis and stellate ganglion block for anterior ischemic neuropathy. Fola Ophthalmol Jpn. 1990; 41(1):59-64.

56. Kelman SE. Intravitreal triamcinolone or bevacizumab for nonarteritic anterior ischemic optic neuropathy: Do they merit further study? J Neuro-Ophthalmol. 2007; 27(3):161-3.

57. Knox DL, Kerrison JB, Green WR. Histopathologic studies of ischemic optic neuropathy. Trans AM Ophthalmol Soc. 2000; 98:203-22. [PubMed: 11190024]

58. Kollarits CR, McCarthy RW, Corrie WS, et al. Norepinephrine therapy of ischemic optic neuropathy. J Clin Neuroophthalmol. 1981; 1(4):283-8. [PubMed: 6213676]

59. Kupersmith MJ, Frohman L, Sanderson M, et al. Aspirin reduces the incidence of second eye NAION: a retrospective study. J Neuroophthalmol. 1997 Dec; 17(4):250-3. [PubMed: 9427177]

60. Landau K, Winterkorn JM, Mailloux LU, et al. 24 hour blood pressure monitoring in patients with anterior ischemic optic neuropathy. Arch Ophthalmol. 1996; 114(5):570-5. [PubMed: 8619767]

61. Lasco F. Les affections vasculaires du nerf optique et leurs manifestations clinique. Opthalmologica. 1961; 142:429-45.

62. Lee AG, Newman NJ. Erectile dysfunction drugs and non-arteritic anterior ischemic optic neuropathy. Am J Ophthalmol. 2005; 140(4):707-8. [PubMed: 16226524]

63. Lee MS, Foroozan R, Kosmorsky GS. Posterior vitreous detachment in AION. Ophthalmology. 2009; 116(3):597-597. [PubMed: 19264223]

64. Lessell S. Nonarteritic anterior ischemic optic neuropathy: enigma variations. Arch Ophthalmol. 1999; 117(3):386-8. [PubMed: 10088818]

65. Levin LA, Danesh-Meyer HV. Hypothesis: a venous etiology for nonarteritic anterior ischemic optic neuropathy. Arch Ophthalmol. 2008; 126(11):1582-5. [PubMed: 19001228]

66. Levin LA. Axonal loss and neuroprotection in optic neuropathies. Can J Ophthalmol. 2007; 42(3): 403-8. [PubMed: 17508035]

67. Levin LA. Lessons from the ischemic optic neuropathy decompression trial: a decade later. Arch Ophthalmol. 2007 Nov; 125(11):1570-1. [PubMed: 17998522]

68. Lohr KN. Rating the strength of scientific evidence: relevance for quality improvement programs. Int J Qual Health Care. 2004; 16:9-18. [PubMed: 15020556]

69. Luneau K, Newman NJ, Biousse V. Ischemic optic neuropathies. Neurologist. 2008; 14(6):341-54. [PubMed: 19008740]

70. McLeod D, Marshall J, Kohner EM. Role of axoplasmic transport in the pathophysiology of ischaemic disc swelling. Br J Ophthalmol. 1980; 64:247-261. [PubMed: 6155935]

71. Miyake Y, Yanagida K, Yagasaki K. Clinical application of EER (electrically evoked response). (1) Analysis of EER in normal subjects (author's transl). Nippon Ganka Gakkai Zasshi (Acta Soc Ophthalmol Jpn). 1980; 84(6):354-60.

72. Modarres M, Sanjari MS, Falavarjani KG. Vitrectomy and release of presumed epipapillary vitreous traction of nonarteritic anterior ischemic optic neuropathy associated with partial posterior vitreous detachment. Ophthalmol. 2007; 114(2):340-4.

73. Mojon DS, Hedges TR, Ehrenberg B, et al. Association between sleep apnea syndrome and nonarteritic anterior ischemic optic neuropathy. Arch Ophthalmol. 2002; 120(5):601-5. [PubMed: 12003609] 
74. Morimoto T, Miyoshi T, Fujikado T, et al. Electrical stimulation enhances the survival of axotomized retinal ganglion cells in vivo. Neuroreport. 2002; 13(2):227-30. [PubMed: 11893915]

75. Murphy MA, Murphy JF. Amiodarone and optic neuropathy: the heart of the matter. J Neuroophthalmol. 2005; 25(3):232-6.

76. Newman NJ, Scherer R, Langenberg P, et al. The fellow eye in NAION: report from the ischemic optic neuropathy decompression trial follow-up study. Am J Ophthalmol. 2002; 134(3):317-28. [PubMed: 12208242]

77. Onda E, Cioffi GA, Bacon DR, Van Buskirk EM. Microvasculature of the human optic nerve. Am J Ophthalmol. 1995; 120(1):92-102. [PubMed: 7611333]

78. Osborne NN, Cazevieille C, Carvalho AL, et al. In vivo and in vitro experiments show that betaxolol is a retinal neuroprotective agent. Brain Res. 1997; 751(1):113-23. [PubMed: 9098574]

79. Preechawat P, Beau BB, Newman NJ, Biousse V. Anterior ischemic optic neuropathy in patients younger than 50 years. Am J Ophthalmol. 2007; 144(6):653-60.

80. Purvin V, King R, Kawasaki A, et al. Anterior ischemic optic neuropathy in eyes with optic disc drusen. Arch Ophthalmol. 2004; 122(1):48-53. [PubMed: 14718294]

81. Roth DB, Verma V, Realini T, et al. Long-term incidence and timing of intraocular hypertension after intravitreal triamcinolone acetonide injection. Ophthalmology. 2009; 116:455-60. [PubMed: 19157561]

82. Sacco RL, Adams R, Albers G, et al. Guidelines for prevention of stroke in patients with ischemic stroke or transient ischemic attack: a statement for healthcare professionals from the American Heart Association/American Stroke Association Council on Stroke: co-sponsored by the Council on Cardiovascular Radiology and Intervention: the American Academy of Neurology affirms the value of this guideline. Stroke. 2006; 37(2):577-617. [PubMed: 16432246]

83. Salomon O, Huna-Baron R, Steinberg DM, et al. Role of aspirin in reducing the frequency of second eye involvement in patients with non-arteritic anterior ischaemic optic neuropathy. Eye. 1999; 13(Pt 3a):357-9. [PubMed: 10624433]

84. Saraux H, Murat JP. Les pseudo-papillites d'origine vasculaire. Ann Ocul (Paris). 1967; 200(1):119. [PubMed: 6029561]

85. Sawle GV, James CB, Russell RW. The natural history of nonarteritic anterior ischemic optic neuropathy. J Neurol Neurosurg Psychiatry. 1990; 53(10):830-3. [PubMed: 2266361]

86. Scherer RW, Feldon SE, Levin L, et al. Visual fields at follow-up in the Ischemic Optic Neuropathy Decompression Trial: evaluation in change of pattern defect and severity over time. Ophthalmol. 2008; 115(10):1809-17.

87. Slater BJ, Mehrabian Z, Guo Y, et al. Rodent anterior ischemic optic neuropathy (rAION) induces regional retinal ganglion cell apoptosis with a unique temporal pattern. Invest Ophthalmol Vis Sci. 2008; 49(8):3671-6. [PubMed: 18660428]

88. Soheilian M, Koochek A, Yazdani S, et al. Transvitreal optic neurotomy for nonarteritic anterior ischemic optic neuropathy. Retina. 2003; 23(5):692-7. [PubMed: 14574257]

89. Stelmack JA, Tang XC, Reda DJ, et al. Outcomes of the Veterans Affairs Low Vision Intervention Trial (LOVIT). Arch Ophthalmol. 2008; 126(5):608-17. [PubMed: 18474769]

90. Strenn K, Matulla B, Wolzt M, et al. Reversal of endothelin-1-induced ocular hemodynamic effects by low-dose nifedipine in humans. Clin Pharmacol Ther. 1998; 63(1):54-63. [PubMed: 9465842]

91. Vidal-Sanz M, Lafuente MP, Mayor S, de Imperial JM, Villegas-Perez MP. Retinal ganglion cell death induced by retinal ischemia. Neuroprotective effects of two alpha-2 agonists. Surv Ophthalmol. 2001; 45(3):261-7.

92. Wen R, Cheng T, Li Y, Cao W, Steinberg RH. Alpha 2- adrenergic agonists induce basic fibroblast growth factor expression in photoreceptors in vivo and ameliorate light damage. J Neurosci. 1996; 16(19):5986-92. [PubMed: 8815881]

93. Wilhelm B, Lüdtke H, Wilhelm H. BRAION Study Group. Efficacy and tolerability of $0.2 \%$ brimonidine tartrate for the treatment of acute non-arteritic anterior ischemic optic neuropathy (NAION): a 3-month, double-masked, randomised, placebo-controlled trial. Graefes Arch Clin Exp Ophthalmol. 2006 May; 244(5):551-8. [PubMed: 16151785] 
94. Wood JP, DeSantis L, Chao HM, et al. Topically applied betaxolol attenuates ischaemia-induced effects to the rat retina and stimulates BDNF mRNA. Exp Eye Res. 2001; 72(1):79-86. [PubMed: 11133185]

95. Yaman A, Selver OB, Saatci AO, et al. Intravitreal triamcinolone acetonide injection for acute nonarteritic anterior ischemic optic neuropathy. Clin Exp Optom. 2008; 91(6):561-4. [PubMed: 18976422]

96. Yoles E, Wheeler LA, Schwartz M. Alpha-2 adrenoreceptor agonists are neuroprotective in a rat model of optic nerve degeneration. Invest Ophthalmol Vis Sci. 1999; 40(1):65-73. [PubMed: 9888428] 

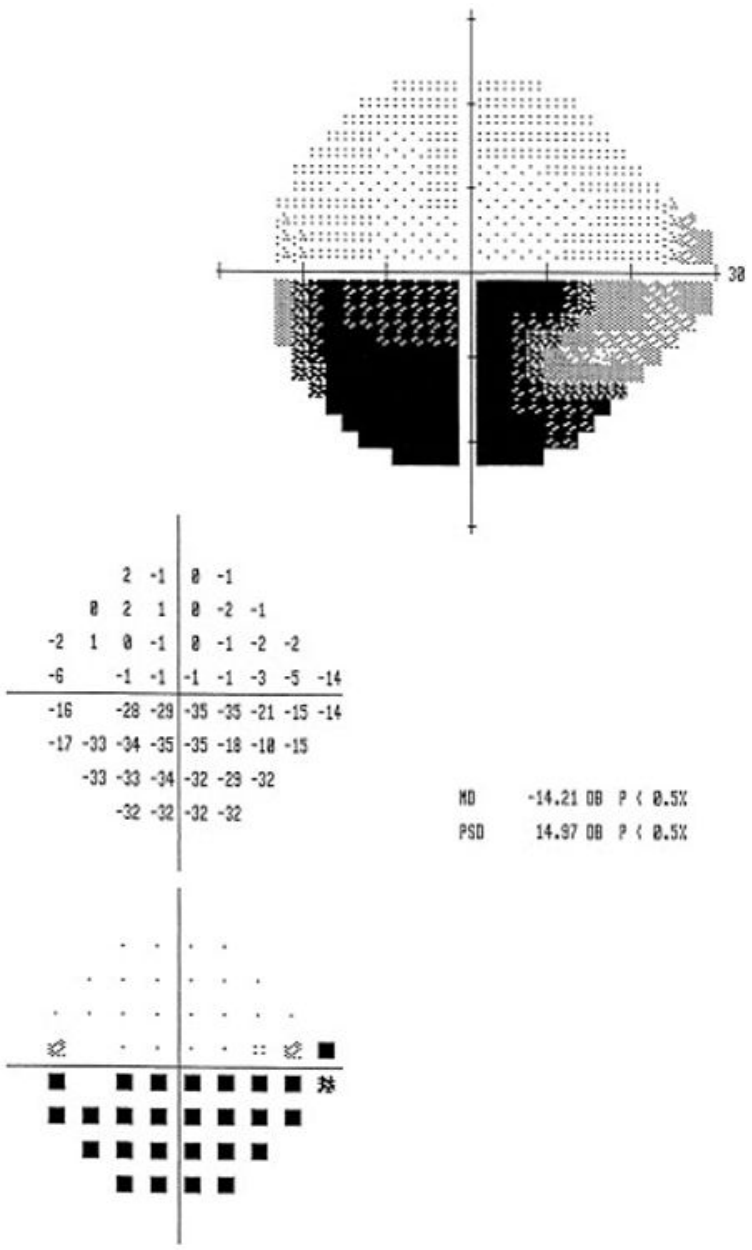

$-14.2108<<8.5 \%$

PSD $\quad 14.97$ OB $?<8.5 \%$

Figure 1.

A 62 year old man presented with a 3 day history of painless decreased vision in the left eye, and initial visual acuity of 20/20 on the right, and 20/40 on the left. Humphrey visual field, 24-2 SITA-FAST protocol, showed an inferior altitudinal defect in the left eye characteristic of NAION. 


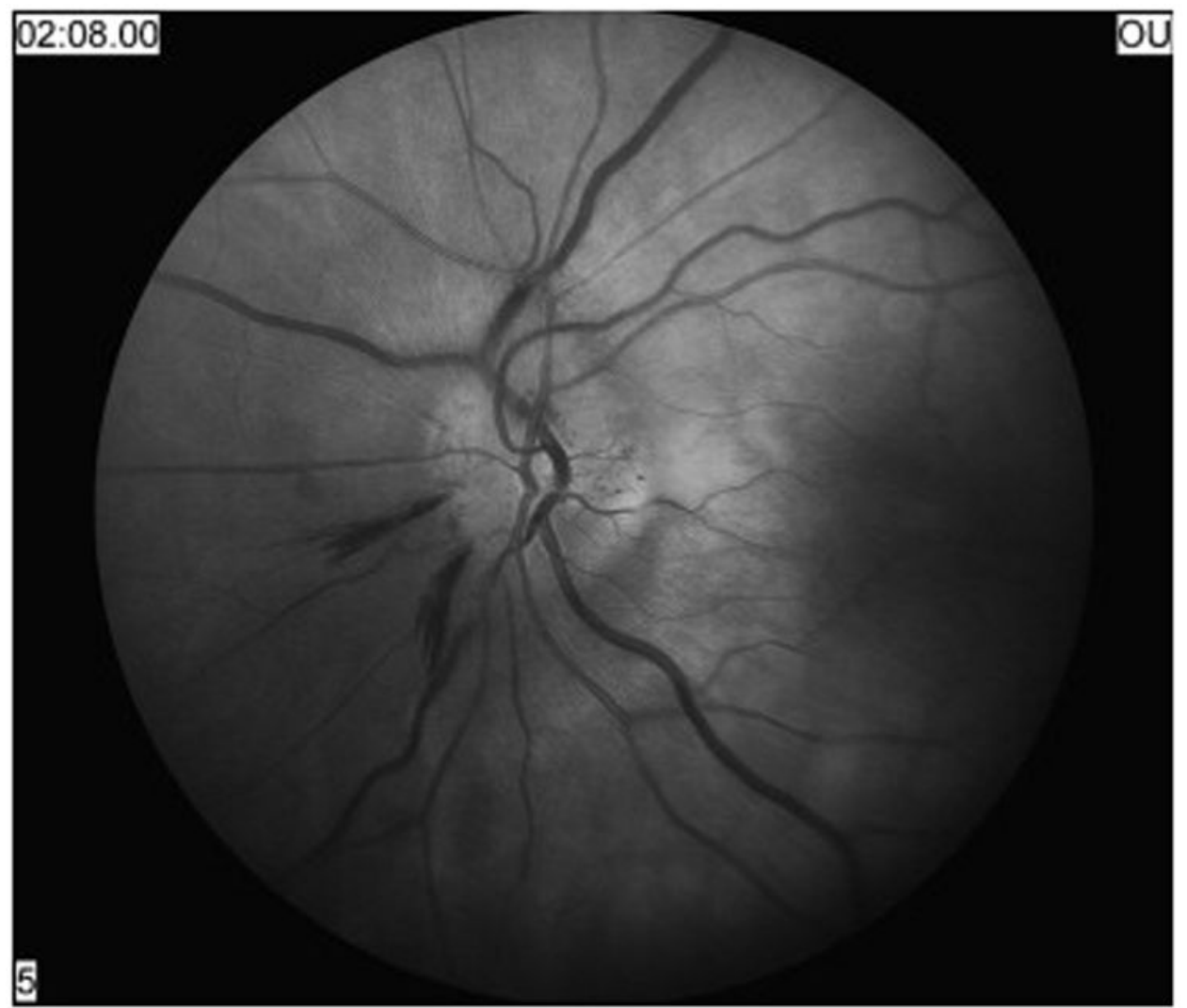

Figure 2.

Optic nerve appearance during the acute phase (3 days after onset of decreased vision) of typical nonarteritic anterior ischemic optic neuropathy showing diffuse disc edema with peripapillary hemorrhages. 


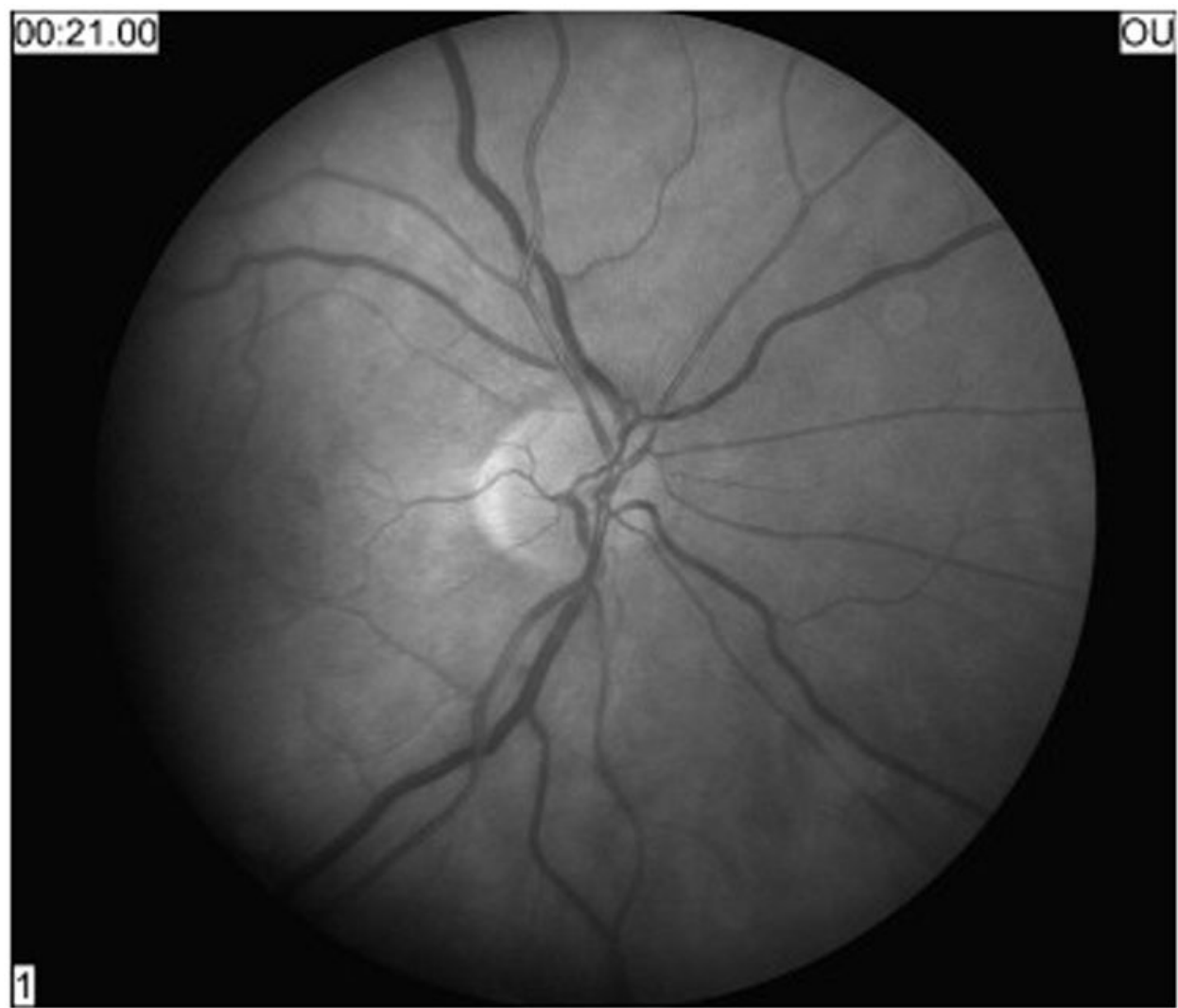

Figure 3.

On fundus examination, the patient's fellow eye showed a small optic disc with cup to disc ratio of less than 0.1 , the classic "disc at risk" for nonarteritic anterior ischemic optic neuropathy. 


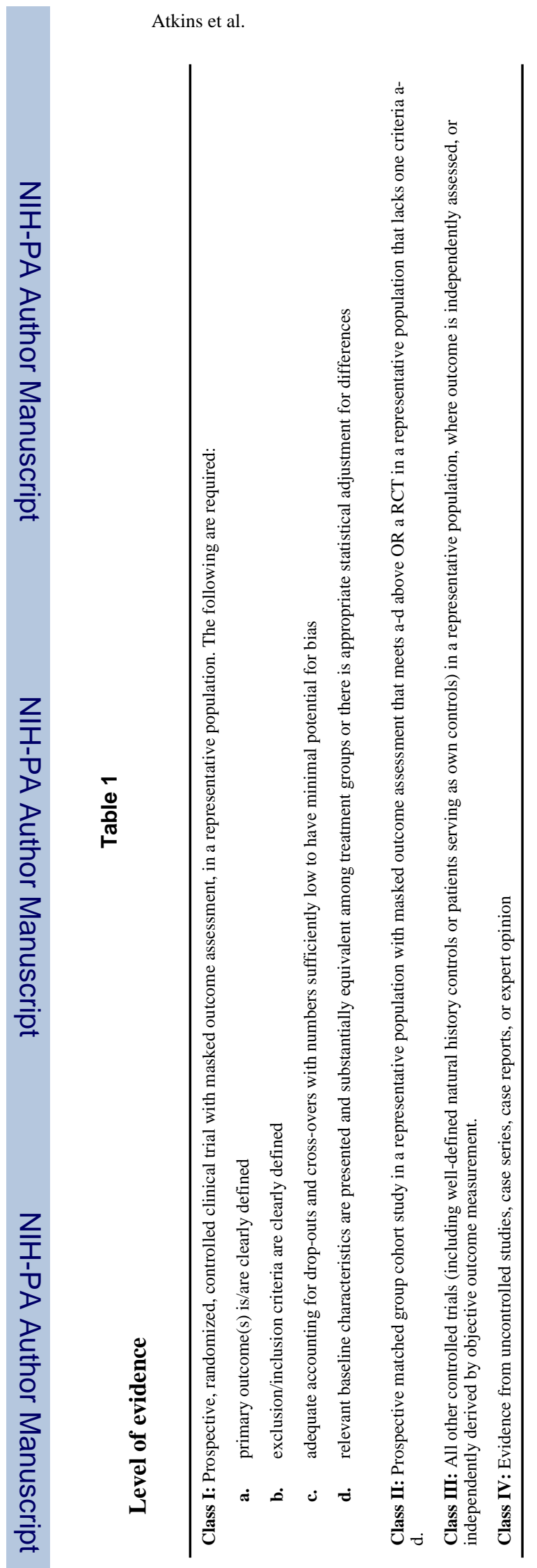

Surv Ophthalmol. Author manuscript; available in PMC 2013 July 24. 


\begin{tabular}{|c|c|c|c|c|c|c|c|c|c|c|c|c|c|c|}
\hline 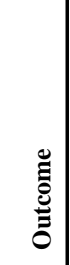 & 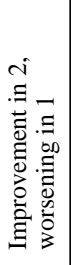 & 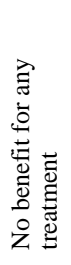 & 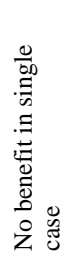 & 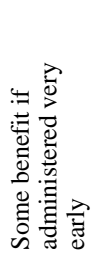 & 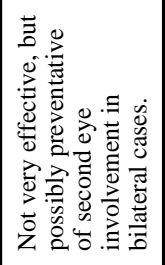 & 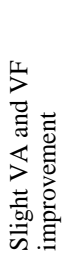 & 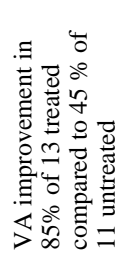 & 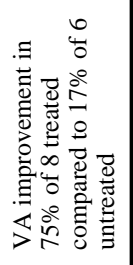 & 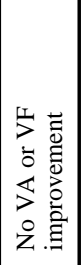 & 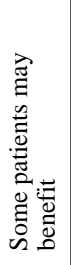 & 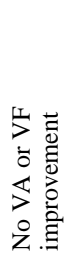 & 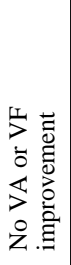 & 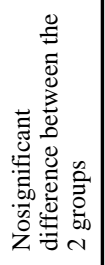 & 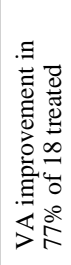 \\
\hline 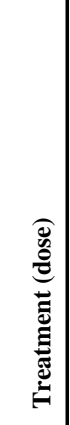 & 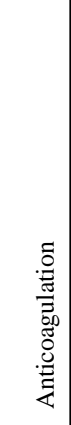 & 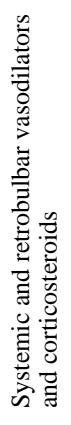 & 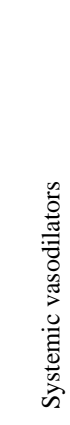 & 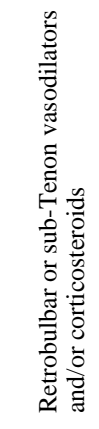 & 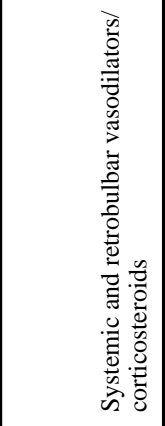 & 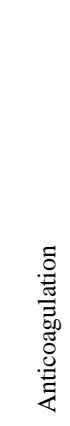 & 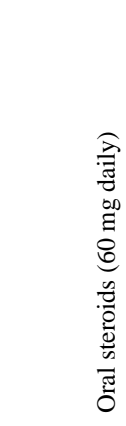 & 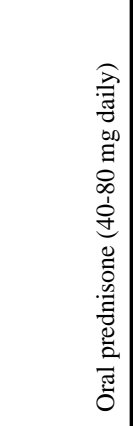 & 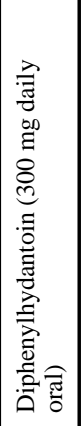 & 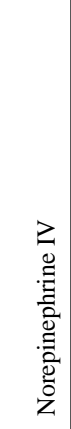 & 悬 & 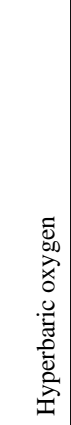 & 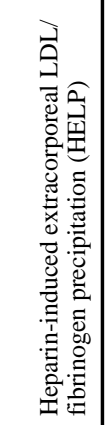 & 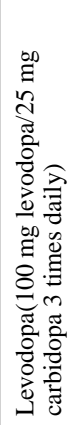 \\
\hline 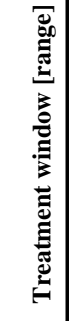 & $\overleftrightarrow{z}$ & $\overleftrightarrow{\mathbb{z}}$ & $\overleftrightarrow{z}$ & $\overleftrightarrow{z}$ & $\overleftrightarrow{\mathbb{z}}$ & $\overleftrightarrow{z}$ & $\overleftrightarrow{z}$ & $\overleftrightarrow{z}$ & 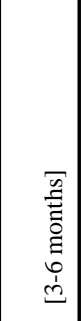 & $\mathbb{z}$ & $\mathbb{z}$ & 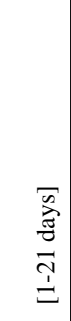 & 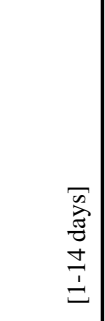 & 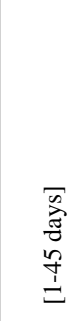 \\
\hline 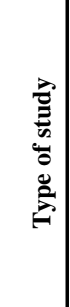 & $\begin{array}{l}\mathscr{s} \\
\stackrel{\tilde{D}}{0} \\
0 \\
0 \\
\tilde{y} \\
\tilde{y}\end{array}$ & 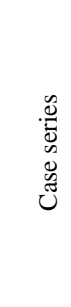 & 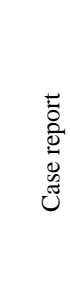 & 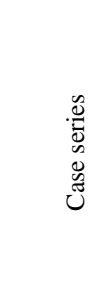 & 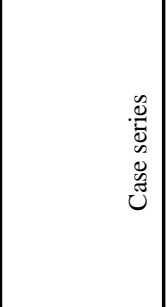 & 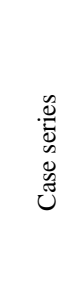 & 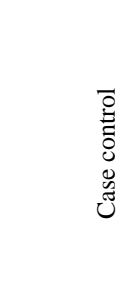 & 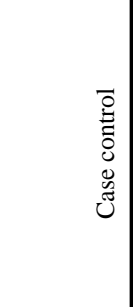 & 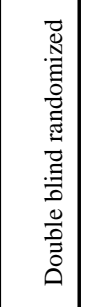 & 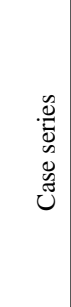 & 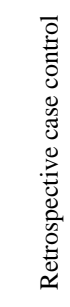 & $\begin{array}{l}\overline{0} \\
\stackrel{0}{0} \\
0 \\
0 \\
\tilde{J} \\
\tilde{J}\end{array}$ & 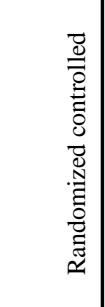 & 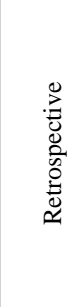 \\
\hline 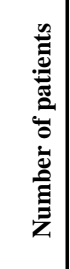 & $\frac{\bar{\pi}}{0}$ & 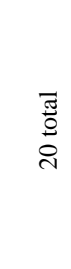 & 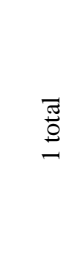 & $\begin{array}{l}\frac{\vec{J}}{0} \\
+\end{array}$ & 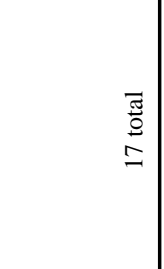 & $\begin{array}{l}\text { ज्ञू } \\
\stackrel{5}{0}\end{array}$ & 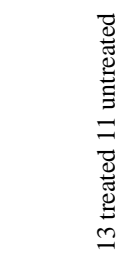 & 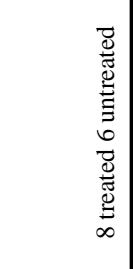 & 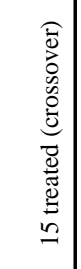 & $\begin{array}{c}\frac{\bar{\sigma}}{0} \\
\stackrel{0}{m}\end{array}$ & 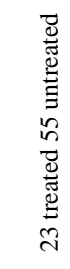 & 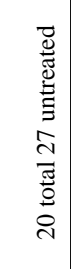 & 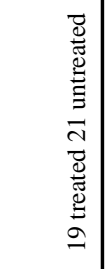 & 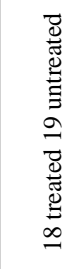 \\
\hline 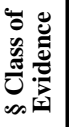 & $\geq$ & $\geq$ & $z$ & $z$ & $z$ & $z$ & $\Xi$ & $\Xi$ & $=$ & $z$ & $\Xi$ & $\Xi$ & $\Xi$ & $\Xi$ \\
\hline 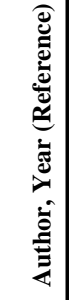 & 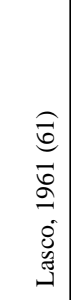 & 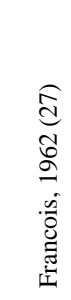 & 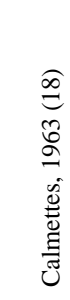 & 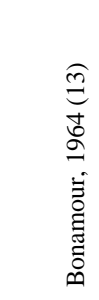 & 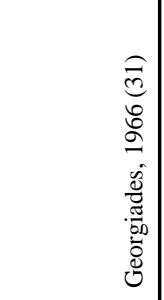 & 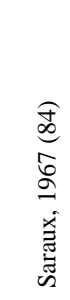 & 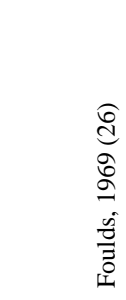 & 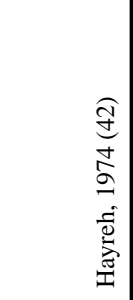 & 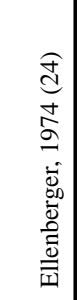 & 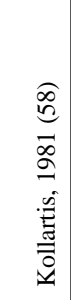 & 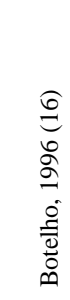 & 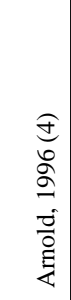 & 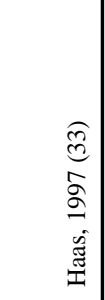 & $\begin{array}{l}\text { त्र } \\
8 \\
8 \\
0 \\
0 \\
0 \\
0 \\
0 \\
0\end{array}$ \\
\hline
\end{tabular}




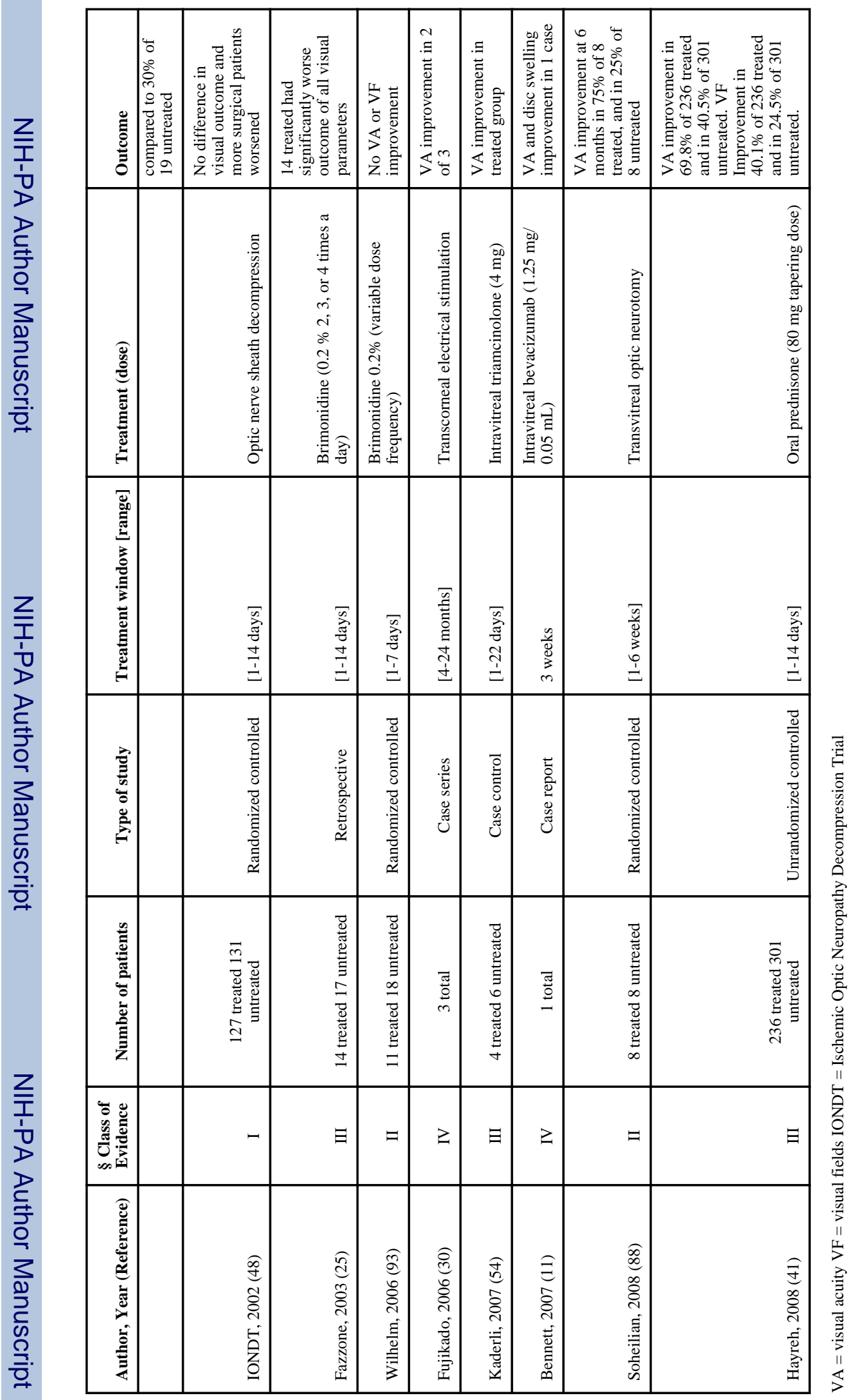

Surv Ophthalmol. Author manuscript; available in PMC 2013 July 24. 


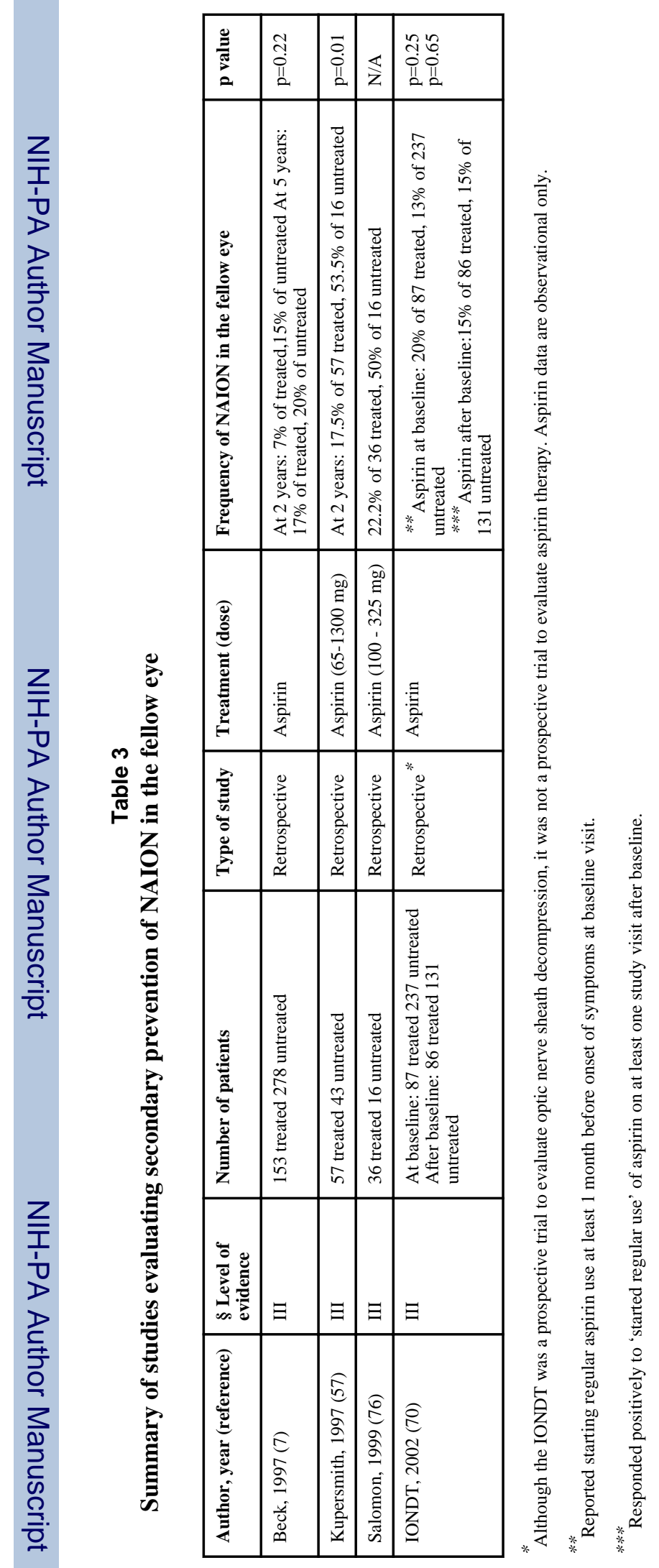

Surv Ophthalmol. Author manuscript; available in PMC 2013 July 24. 